\title{
Wear of carbide inserts with complex surface treatment when milling nickel alloy
}

\author{
Sergey Fedorov, Min Htet Swe, Alexey Kapitanov, and Sergey Egorov \\ Moscow State University of Technology "STANKIN", 1 Vadkovsky per., Moscow GSP-4, 127055, Russian Federation
}

Received: 1 September 2017 / Accepted: 1 December 2017

\begin{abstract}
One of the effective ways of strengthening hard alloys is the creating structure layers on their surface with the gradient distribution of physical and mechanical properties between the wear-resistant coating and the base material. The article discusses the influence of the near-surface layer which is modified by low-energy high-current electron-beam alloying and the upper anti-friction layer in a multi-component coating on the wear mechanism of the replaceable multifaceted plates in the dry milling of the difficult to machine nickel alloys.
\end{abstract}

Keywords: Carbide inserts / multi-component coating / replaceable multifaceted plates / nickel alloys

\section{Introduction}

Nowadays wear-resistant coating technology has become an integral part of our lives. Despite all the diversity of today's hard-alloy cutting tools, it is not easy to find any of them that are not hardened. Over the period of a little over 40 years, the coatings are developed from a simple (judging from today's perspective) titanium nitride to compound, gradient, multilayer, nanoscale coatings, etc. Modern compounds make it possible to ensure not only a high strength of interlaminar adhesion and hardness-viscosity balance but also a low friction factor, high abrasion resistance, diffusion and heat flux barrier properties [1-4]. Major producers of cutting tools, such as Kennametal (USA), Krupp Widia (Germany), Sandvik Coromant (Sweden) and Metalwork Plansee AG (Austria), work on this problem which is governed by their researches. With the use of automated installations, it is possible to form a complex combination coating with a multilayer composite architecture, nanometer-scale structure, alternative nanoscale thickness layers of various composition and multifunction. The first generations of coatings were sufficient to indicate chemical composition, but now, it is needed for more options because of the complexity of the description, they should be necessarily given by proper names.

However, innovations in new grades of hard alloys should be noted, while Krupp Widia and DEW are undisputed leaders. Without these new alloys, wear-

\footnotetext{
* e-mail: av.kapitanov@stankin.ru
}

resistant coating with all their benefits would have been out of the question. Technologies of high-temperature powder synthesis, hot isostatic pressing, automated nanosized powder production and other processes make it possible to increase cutting zone temperature by 200 $300^{\circ} \mathrm{C}$ and ensure low resistance variance.

Nevertheless, there exists a potential area of enhancing the properties of hard-alloy tools. One of such promising ways is the modification of working surfaces due to the thermal strengthening and diffusion saturation of alloying elements [5]. The obtained experimental results indicate the possibility of creating wear resistant layer on the surface of hard alloy using electron-beam alloying technology. Such layers were obtained, thanks to the initiation of exothermic chemical reactions between substrate and thin film deposited on it. It has been discovered the formation of new phase components.

Getting off the non-equilibrium structure which obtained in the course of pulsed electron-beam alloying, which is created in the surface layer of the sintered alloy is a promising treatment of hard alloy consisting of the wearresistant complex before applying the wear-resistant coating. The use of such technology in a wide range allows controlling the structure and properties of modified nearsurface layers and wear-resistant coatings due to changes in major modes of the process [6,7].

In this paper, we would like to compare the behavior of hard-alloy tools having several types of wear-resistant coatings and with precursory surface alloying under the conditions of intensive wear without the use of coolant in milling heat-resistant nickel alloys which is known as material hard to machine. 


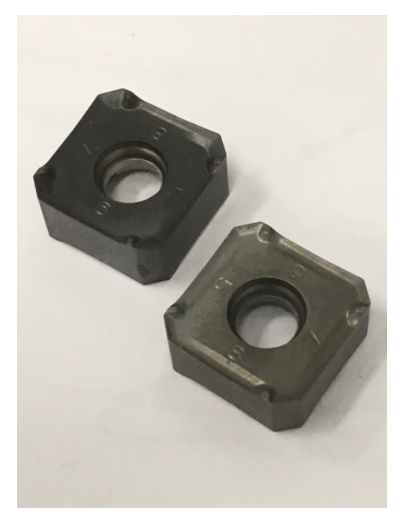

Fig. 1. Replaceable indexable 345R-1305E-KL milling inserts.

\section{Methods and materials}

To learn more about differences in the wear that is occurred between the tools subjected to a combined surface treatment, includes electron-beam alloying of the surface, with subsequent application of a wear-resistant coating, and the tool that is coated only, a series of experiments in milling heat-resistant alloy $\mathrm{NiCr}_{20} \mathrm{TiAl}$ was investigated.

For experiments, multifaceted replaceable milling inserts with uncoated fine-grained alloy H13A with a good balance of wear resistance and toughness produced by Sandvik Coromant (N15, S20, K25) were used. The alloy is suitable for studying of hardening processes in the carbide tools, including surface alloying, because the alloy has one of the most chemically simple compositions, which facilitates studying of structural features of the modified material.

For milling operations, 345R-1305E-KL inserts without coating (cutting group K) were used (Fig. 1). Modified inserts in the course of experiments were compared with a 345R13T5E-ML insert (cutting group M) having a proprietary wear resistant coating. Microhardness of the coating was $\mathrm{HV}_{25}=2370$. Chemical element distribution within the coating was studied using a KAlpha photoelectron spectrometer produced by Thermo Fisher Scientific (UK). In this study, (AlTi)N-based multilayer composite coating with an antifriction surface layer is used. According to some data, such inserts have the resistance, which is 22.5 times higher than inserts with the standard multilayer coating [8].

Some inserts were subjected to alloying of the nearsurface layer before application of a wear-resistant coating. The treatment was performed using a RITM-SP station which is featuring the combination of a source of lowenergy high-current electron-beams RITM and two magnetron-sputtering systems in the same vacuum chamber. The installation allows the deposition of thin films on the surface of desired products and subsequent liquid-phase to mix of the film and substrate materials by pulsed electron-beam $[9,10]$. The processing area is about $50 \mathrm{~cm}^{2}$ for one time.

Depositing of a thin layer of carbide-forming chemicals (in this particular case targets of Nb70Hf22Ti8 alloy) on the surface of the tool before its treatment with electronbeam makes it possible to achieve a modified structure on the cutting surfaces owing to a heat-generating reaction between the metal of the film and the carbon contained in the hard alloy. The external layer is enriched with $\gamma$-WC and (NbHf)C high-melting carbide phases. These compounds with similar FCC structure are able to form non-stoichiometry structures with the non-stoichiometry range of $0.5-0.97$, to prevent decarburization effects $[11,12]$. The maximum attainable thickness to obtain the modified structure is 3$4 \mu \mathrm{m}$. To ensure a complete transformation, it is usually sufficient to perform five or six electron-beam pulses.

Finally, it was applied at $\pi 80+$ and $\pi 311+$ Deposited diamond-like carbon(DLC) installations produced by Platit AG (Switzerland). Inserts with wear resistance coatings are tested:

TiAlN-ML (proprietary name) multilayer coating is made up of alternating nitride phase layers with varying $\mathrm{Al}$ and $\mathrm{Ti}$ content, and it is grown on an adhesive TiN layer. These were treated with a gradient layer of $(\mathrm{TiAl}) \mathrm{N}$ which had been increased in concentration towards the coating surface (Fig. 2a). Microhardness of this coating $\mathrm{HV}_{25}$ was 2850.

For the second series of experiments, it was chosen TiAlN-ML-coated inserts which were further deposited diamond-like carbon (DLC) film (the information of its structure is given in Fig. 3 and Tab. 1), which is characterized by an abnormally low friction coefficient. A drawback of DLC coatings is their inability to withstand high temperatures. Manufacturers of tools with these coatings warn against heating them to more than $450{ }^{\circ} \mathrm{C}$ [13]. It is clear that cutting off the nickel alloys without coolant, even for interrupted cuts, will result in a situation where the area adjacent to the tool's cutting edge would heat to more higher temperature. However, this area is relatively small, and the coating will affect the greater area. Microhardness of the DLC coating $\mathrm{HV}_{10}$ was 3030 .

Inserts with a nATCRo3 coating, which is combined of CrTiN and AlTiN layer sequence and an $\mathrm{AlTiCrN} / \mathrm{SiN}$ nanocomposite coating (Fig. 2b), were also tested. A twophase structure of the last layer is constituted by AlTiCrN crystals with a grain size of up to $5 \mathrm{~nm}$ and is distributed equally to $\mathrm{Si}_{3} \mathrm{~N}_{4}$ in the amorphous phase. The phase interfaces are being the area of intensive dissipation of energy, diverge the cracks in the coating from their paths and inhibit their propagation rate, which leads to the hardening of the material [12].

Before application of the wear-resistant coating, some inserts were subjected to the electron-beam surface alloying. As in the previous scenario, behavior of the experimental inserts was compared with the (AlTi)N coated Sandvik insert.

The effect of the electron-beam surface alloying on the operation of replaceable inserts was studied during face milling (Fig. 4) of a forged blank made of the $\mathrm{NiCr}_{20} \mathrm{TiAl}$ alloy having the hardness of $330 \mathrm{HB}$. Milling was performed using a vertical milling console machine VM 127M, under a symmetrical scheme.

Milling was performed in two cutting modes: cutting speed $v=95 \mathrm{~m} / \mathrm{min}$, depth of cut $t=0.2 \mathrm{~mm}$, feed $s=0.1 \mathrm{~mm} /$ tooth (cutting mode 1) and $v=38 \mathrm{~m} / \mathrm{min}$, $t=0.4 \mathrm{~mm}, s=0.2 \mathrm{~mm} /$ tooth (cutting mode 2). Each point was obtained by cutting a new top. If chipping occurred in the cutting process, then a vertex are rejected. 


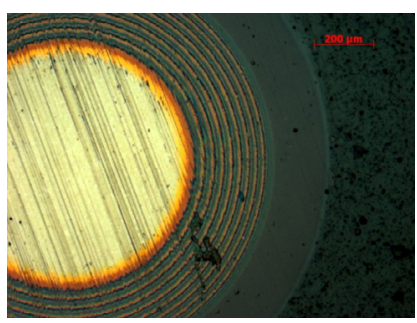

(a)

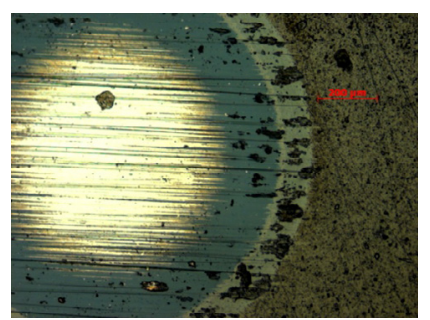

(b)
Fig. 2. Grinding image of coatings: (a) TiAlN-ML, (b) nATCRo ${ }^{3}$.

C1s Scan

40 Scans, $12 \mathrm{~m} 42.0 \mathrm{~s}, 300 \mu \mathrm{m}$, CAE 20.0

$0.05 \mathrm{eV}$

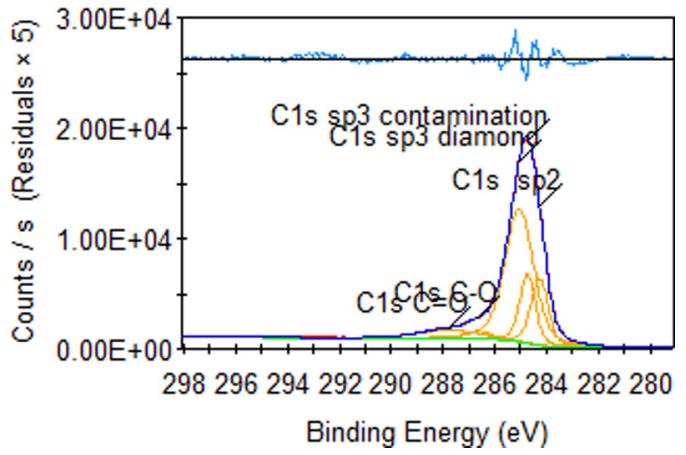

Fig. 3. Characteristic carbon line pattern of the DLC coating.

To evaluate interactional friction between inserts with various coatings and machined materials, scratch tests were performed using a tempered steel ball as an indenter. At the same time on traces of settings of the coating samples was observed.

Changes in the cutting edge corner radius $\rho$ in the original state and after the machining process of the insert were measured by the MicroCADlite device (GFM, Germany). The character of wear area was studied by using VEGA 3 LMH scanning electron microscope (TESCAN, Czech Republic).

\section{Results}

In this paper, the solution of the problem to affect the nature of tool wear mechanism by changing the nature of friction at the front and rear cutter surfaces due to the creation of the layer containing more heat-resistant and more rigid than the crystals of WC carbide phase was proposed. The radius of rounding of the cutting edge formed in the process of wear of the working surfaces becomes much smaller and, consequently, facilitates the gathering of chips.

The measured corner radius of the cutting edge of the studied inserts before the test showed that it is amounted to value about $50 \mu \mathrm{m}$ in all cases.

Data is concerned with the wear on the rear surface of milling replaceable multifaceted plates $\mathrm{H} 13 \mathrm{~A}$ with a variety of processing when face milling of alloy $\mathrm{NiCr}_{20} \mathrm{TiAl}$ is shown in Figure 5.
Table 1. Carbon phase content in the DLC coating (elemental ID and quantification).

\begin{tabular}{|c|c|c|c|}
\hline Name & Peak BE & FWHM $(\mathrm{eV})$ & Atomic $\%$ \\
\hline C1s sp2 & 284.3 & 0.8 & 17.00 \\
\hline C1s sp3 contamination & 284.7 & 0.7 & 16.06 \\
\hline C1s sp3 diamond & 285.0 & 1.3 & 56.33 \\
\hline $\mathrm{C} 1 \mathrm{~s} \mathrm{C}-\mathrm{O}$ & 286.6 & 1.1 & 2.92 \\
\hline $\mathrm{C} 1 \mathrm{~s} \mathrm{C}=\mathrm{O}$ & 287.8 & 2.9 & 7.68 \\
\hline
\end{tabular}

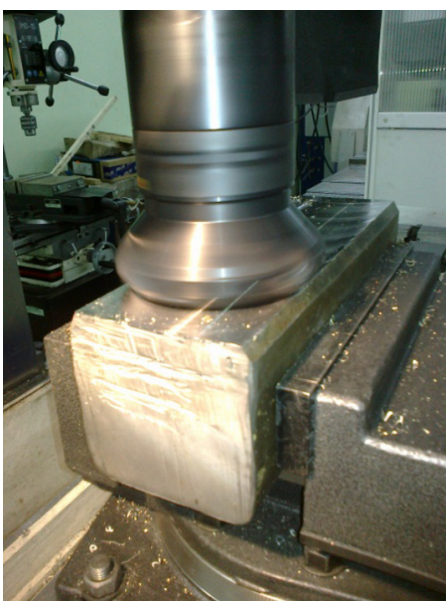

Fig. 4. Milling of a $\mathrm{NiCr}_{20} \mathrm{TiAl}$ alloy blank.

By comparing lines 1 and 3 in Figure 5, the effectiveness of operation of the surface antifriction layer in Sandvik insert's coating can be expressly determined. This insert worked almost twice longer than the insert which has a similar coating (TiAlN-ML) and was characterized by considerable buildup formation of the machined material on the areas adjacent to the cutting edge. At the catastrophic wear area, where the effect of the anti-friction layer is canceled out, abrasive wear of the tool prevails, and the curves behave almost equally.

A somewhat different phenomenon can be observed when milling with a tool subjected to combined surface treatment (line 2). Due to niobium and hafnium carbides alloying of the near-surface layer underlying the coating, the insert resists abrasive wear much better. At the cutting regimes specified above, its resistance is two times higher than of a Sandvik insert and three times as high as a TiAlNML coated insert, despite the fact that an alloyed insert loses at the initial stage of wear. It should be noted that this is the considerable advantage of tools subjected only to surface alloying which occurs at high cutting speeds when loads on base material substantially increase.

The test results of TiAlN-ML + DLC and nATCRo ${ }^{3}$ coated inserts according to the second scenario are shown in Figure 6. As in the first case, inserts having (TiAl)N Sandvik coating demonstrated the best cutting results at the first stage of machining which was the subject of this research. However, inserts are subjected to combined surface treatment with a few large amplitude values of flank wear; they showed the same wear rate. 


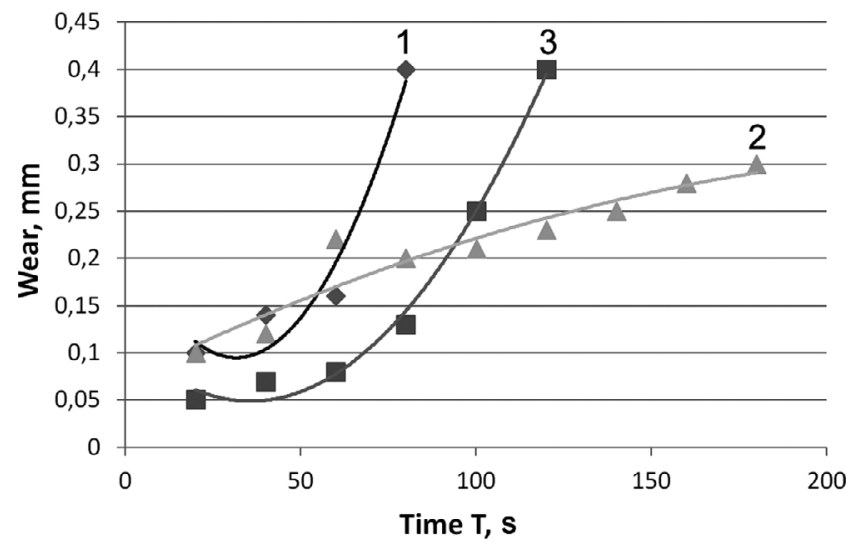

Fig. 5. Rear surface wear of indexable H13A inserts treated differently during face milling of the $\mathrm{NiCr}_{20} \mathrm{TiAl}$ alloy. 1-TiAlNML coated insert, 2-TiAlN-ML coated and surface micro alloyed insert, 3-(AlTi)N coated Sandvik Coromant insert. $v=95 \mathrm{~m} /$ $\min , t=0.2 \mathrm{~mm}, s=0.1 \mathrm{~mm} /$ tooth.

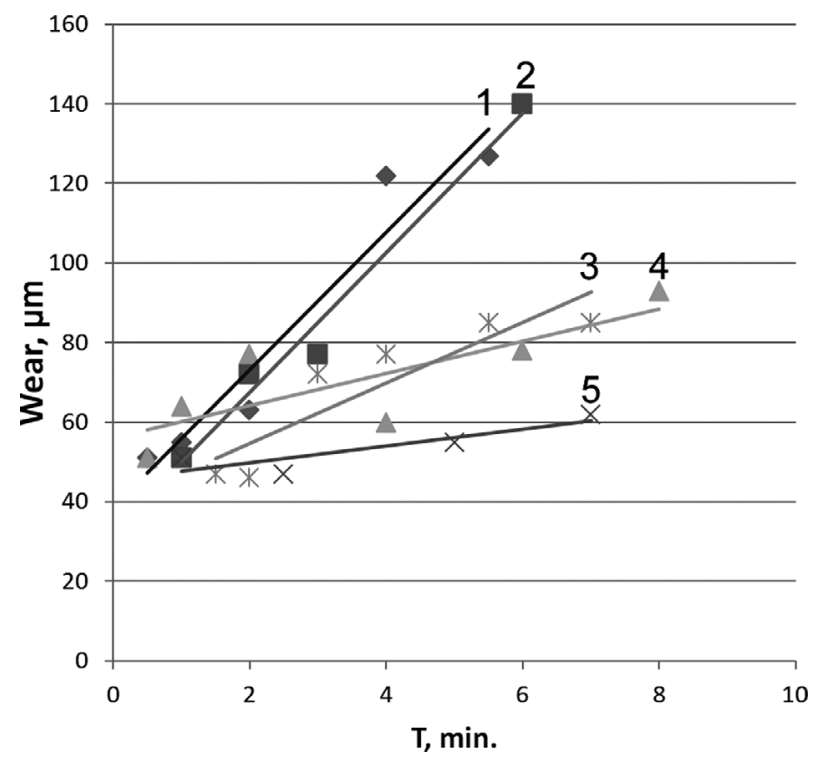

Fig. 6. Trailing surface wear of indexable H13A inserts treated differently during face milling of the $\mathrm{NiCr}_{20} \mathrm{TiAl}$ alloy. 1-TiAlN$\mathrm{ML}+$ DLC coated insert, $2-\mathrm{TiAlN}-\mathrm{ML}+$ DLC coated and surface alloyed insert, $3-$ nATCRo $^{3}$ coated insert, $4-$ nATCRo $^{3}$ coated and surface alloyed insert, $5-(\mathrm{TiAl}) \mathrm{N}$ coated Sandvik insert.

A change in the conditions of friction when cutting due to applied DLC coating manifests primarily in the changing nature of chip formation. Whereas nitride coated inserts demonstrated flow chip formation, carbon coated inserts had more prominent chips curling and fracture. Crater location also is changed due to chip friction against the front surface of the insert. The distance from the middle of the crater to the cutting edge is shortened about three times (Fig. 7).

Results of the experiments are in good agreement with the scratch tests performed using a steel ball. These are DLC-coated inserts with the lowest friction coefficient that have the least tendency to gripping (Fig. 8).

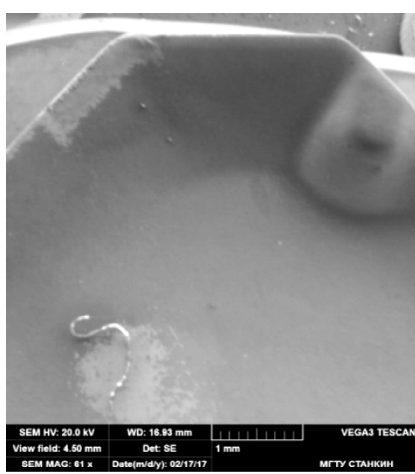

(a)

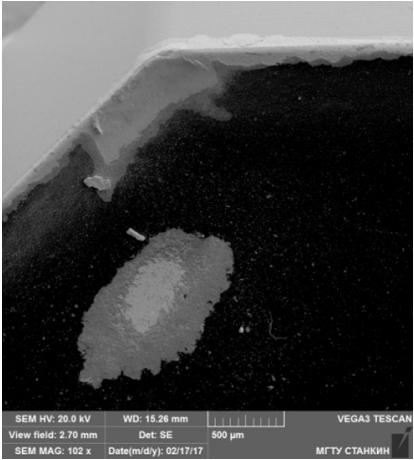

(b)
Fig. 7. A change in crater location caused by friction of chips against the front surface of an insert: (a) (TiAl)N Sandvik, (b) TiAlN-ML + DLC.

Inserts having TiAlN-ML + DLC and nATCRo ${ }^{3}$ coatings, and not subjected to combination treatment, demonstrate considerable buildup formation of nickel alloy at machined surfaces. Figure 9 shows SEM images of the main (Fig. 9a and b) and side (Fig. 9c and d) cutting edges after two minutes of machining. The $\mathrm{ATCRo}^{3}$ coated tool performance act a little better, however, in both cases coating and even base chipping are observed together with machined material buildup, which degrades the tool resistance considerably.

(AlTi)N coated Sandvik inserts display a principally different behavior (Fig. 10). Here, buildup formation on the rear and front surfaces of the tool is much lower. Forming lumps in certain locations of the cutting edge are not spread along the tool as in the case of TiAlN-ML+DLC and nATCRo ${ }^{3}$ coated inserts, but by going into "packs" (Fig. 10a) which break off without causing damage to the tool owing to low adhesion interaction of the coating with the machined nickel alloy.

Figure 11 shows SEM images of cutting-edge areas of worn inserts subjected to combination surface treatment. A particular feature of this treatment is the accumulation of high-melting MC type carbide phases in $3 \mu \mathrm{m}$ nearsurface layer of the hard alloy. Due to extremely high cooling rate caused by electron-beam treatment, these phases remain fine-sized and evenly distributed $[14,15]$. At the same time, due to the reactions of synthesis of new refractory carbides in the liquid and solid phases, it is possible not only to avoid cracking the surface but also it creates a surface free from the cords of the layer with a hardness greater than the hardness of base to $300 \mathrm{HV}$, the depth of 3-4 $\mu \mathrm{m}[16-18]$. Enriched layer with cobalt bonds with Co concentration is up to four times higher more than that of the directly underlying layer which has an adequately high hardness. However, it is somewhat lower than the hardness of the base material. The layer behaves well under microplastic deformation.

Inserts subjected to combination treatment demonstrate a much slower formation of a crater, and their cutting edge can withstand the cutting force and the formation of the buildup of the machined material, which significantly impedes catastrophic wear. No cracks form 


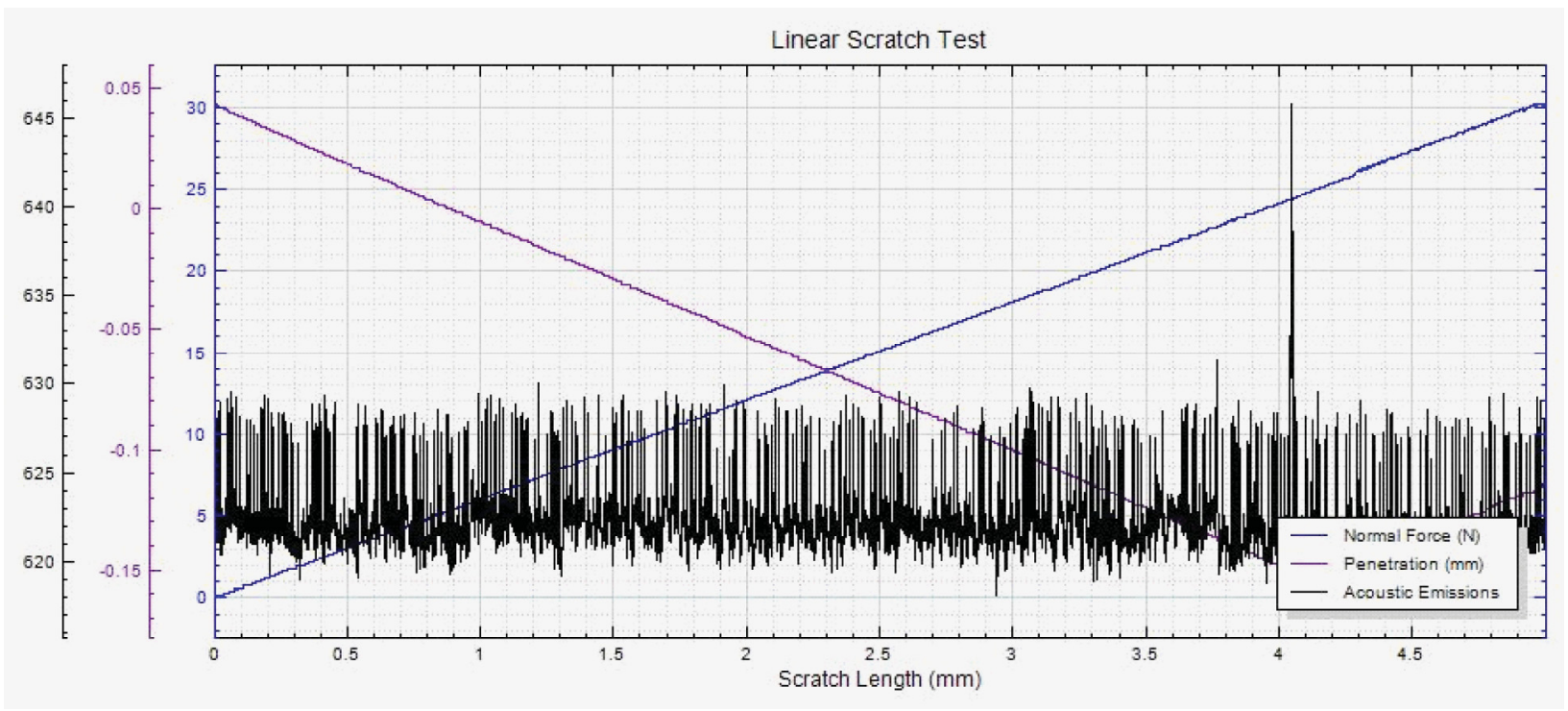

(a)

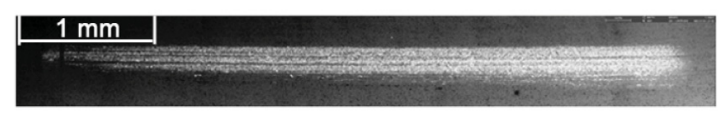

(b)

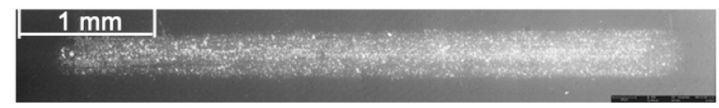

(c)

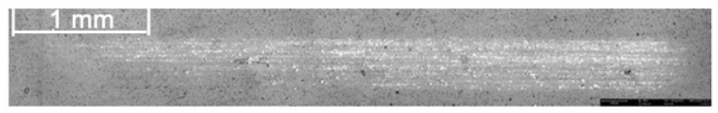

(d)

Fig. 8. Study of the phenomenon of coated insert gripping with steel ball during scratch testing, where (a) is the results of the liner scratch test, (b) is a picture of the specimen with (AlTi)N Sandvik coating, (c) is a picture of the specimen with nATCRo ${ }^{3}$ coating, (d) is a picture of the specimen with TiAlN-ML + DLC coating.

was at the cutting edge. Even in cases when it partially chips, it sharpens itself promptly. Corner radius of the cutting edge lies within $12-15 \mu \mathrm{m}$. For inserts without microalloying, their radius was ranged from 22 to $26 \mu \mathrm{m}$.

\section{Discussion}

Numerous researches in the area of metal machining reveal that the main types of cutting tool wear are adhesion and abrasion wear, which is also accompanied by phenomena associated with fatigue, diffusion and oxidation processes $[19,20]$. Depending on machining conditions, one of these types of wear becomes predominant, although other ones may be presented as well.

Experiments reveal that adhesion wear during machining $[21,22]$ results from particles of material which are broken off the machined surface. These torn particles are transferred onto the surface of the tool and form lumps with a rather high hardness, which is promoted by a high contact temperature on the cutting tool surfaces caused by friction factors, and it is considerably higher than those of structural steels due to an intense adhesion contact. Gripping of chips from the cutting surface and even destruction of bond pads effectively limits the use of a hard alloy tool, especially for intermittent cutting $[23,24]$. The lumps formed during the cutting are unstable: they have continuously removed together with the material of 317 a workpiece and left cavities in the area of their formation. Such lumps are usually formed on the cutting edge.

Abrasive wear of cutting tools and their specific features when machining nickel alloys are well studied [25]. The high abrasiveness of heat-resistant alloys results from intermetallic and carbide inclusions which, being essentially abrasive, cause accelerated wear of cutting edges [26]. While machining, solid inclusions behave as 


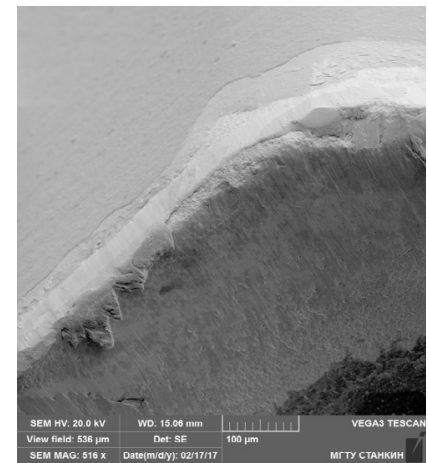

(a)

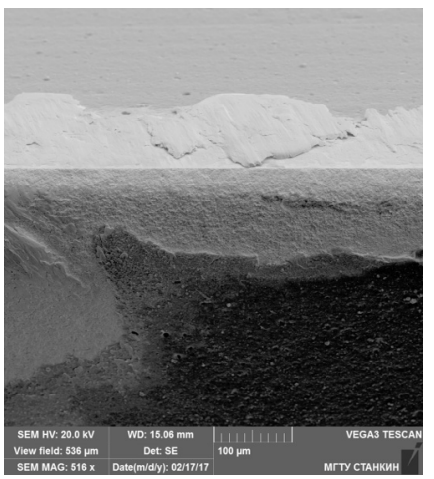

(c)

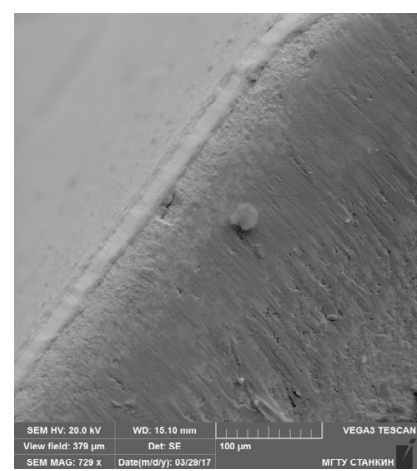

(b)

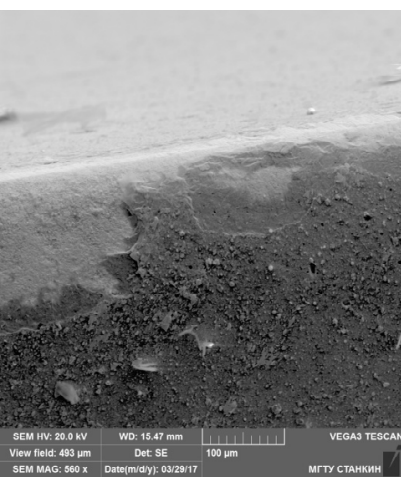

(d)

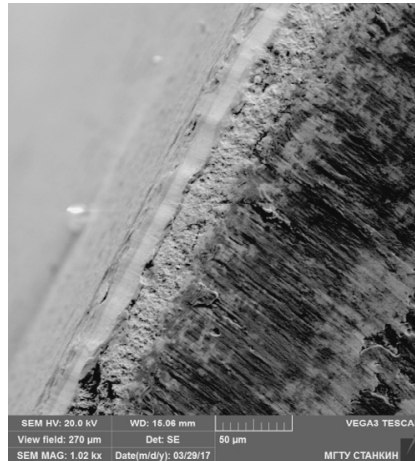

(a)

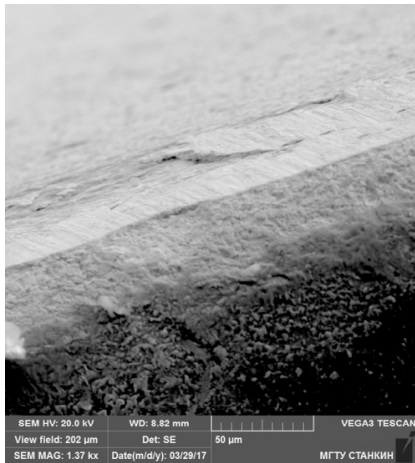

(c)

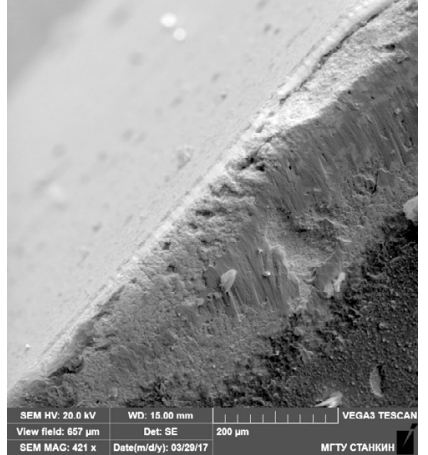

(b)

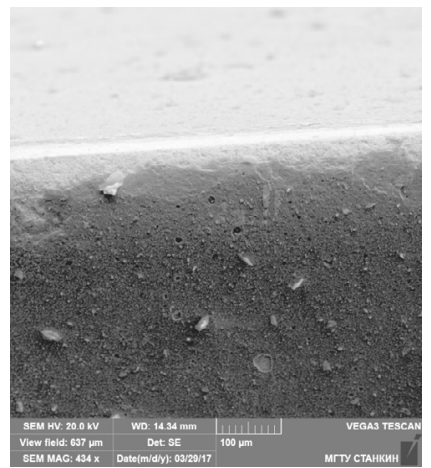

(d)

Fig. 9. Condition of the main ( $a$ and $b$ ) and side (c and d) cutting edges of inserts treated with TiAlNML + DLC (a and c) and nATCRo ${ }^{3}$ coating after two minutes of cutting.

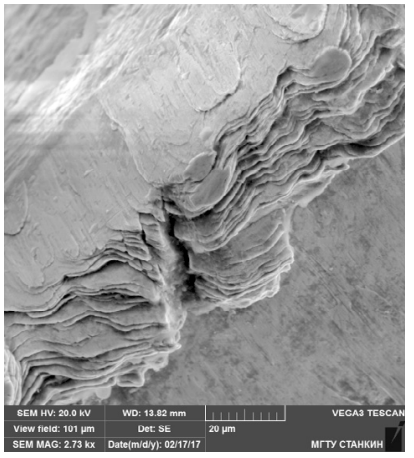

(a)

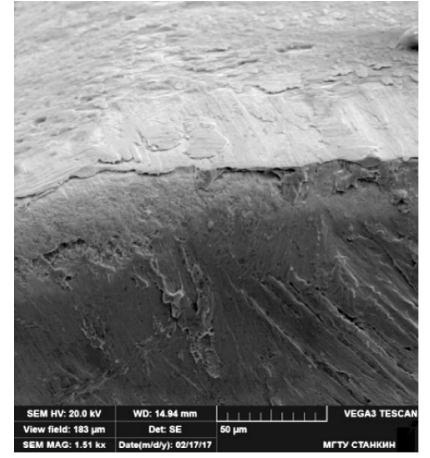

(b)

Fig. 10. Main (a) and side (b) cutting edges of (TiAl)N Sandvik coated insert after four minutes of machining.

penetrating abrasives for the surface of the tool and scrap it. Solid inclusion size and their distribution substantially effect on this process [27].

At the same time, the effect of fission of excessively hard fragments of lumps and buildups will cause such defects as abrasions, grooves, and elongated channels. These particles, which have the hardness comparable to outer layers of cutting face of the tool due to strain hardening, act as an abrasive.

Fig. 11. Condition of the main (a and b) and side (c and d) cutting edges of inserts treated with TiAlN-ML + CROMVIc (a, b) and nATCRo ${ }^{3}$ coatings subjected to microalloying after four minutes of cutting.

Machining of nickel alloys is a complex technological process. Physical and mechanical properties of these alloys not only complicate their machining but also pose strict requirements to the rigidity of machines and wear resistance of tools. Due to considerable efforts applied during machining, cut area overheats and requires additional cooling $[28,29]$. In our experiments, we intentionally refrained from using cutting fluids and performed machining operations at high cutting speeds to provoke accelerated wear of tools.

The focus of prevailing tool wear develops, as a rule, in the area of maximum release of heat, which is mainly defined by conditions of friction of the tool against the machined blank and the resulting chips. In its turn, the blank's surface layer conditions and its surface roughness are essentially affected by the load effect of transformation of the cut allowance into chips due to a plastically deformed transition layer develops, which is defined by processes of self-adjustment of tribal-contacts, and it is responsible for the stagnant zone and lump development. The process involves chips formation zone, tribal-contacts of work surfaces of the tool with chips and the machined surface. The depth of these deformations may vary from several micrometers up to hundredths of a millimeter. The intensity and depth of cold strain hardening propagation grow with the increase of cutting forces and the duration of their effect. 
Most significantly, this pertains to finish operations when the main focus area of wear lies on the main trailing surface. Intensive wear and active buildup of the machined material in this area causes a reduction of primary back angle down to zero values, which results in the growth of plastic strain at tool point. The tool does not so much cut as bends metal. Thermal loads grow, which causes premature failure of the tool.

The varied pattern of buildup and lump formation at the cutting edge should be noted, as evidenced by the altered chip formation process after the electron-beam alloying of the tool's surface. Alteration of the structure and phase composition of the tool material leads to a shift of the buildup formation area from the machined material closer to the tooltip. Noticeably, flowing chips quite often damage unengaged area of the cutting edge. With the purpose to avoid this phenomenon, it seems that the insert geometry should be changed in some way to adapt it to the changed cutting conditions; otherwise, this area should be protected with a coating having a low friction factor.

It was discovered that the formation of cleavages outside the work area does not affect the roughness of the machined surface. With the given cutting modes, roughness was more likely determined by individual properties of the insert, than by the mode of its processing. Spread of $R_{A}$ values for different inserts was $1.6-3.5 \mu \mathrm{m}$.

Some particularities concerning the performance of inserts with combined surface treatment, which includes surface alloying before the application of a wear-resistant coating, can be distinguished. For example, running-in of such inserts occurs faster, and roughness values of the machined surface remain stable for a more extended period.

Another particularity of wear of H13A inserts after the combined treatment is the shift of crater formation closer to the radius part of the tool. It should be noted. However, that corner radius of the cutting edge which is formed during engagement of the machined and generating surfaces [30,31] is smaller, then that in the case of microalloying of a hard-alloy insert before application of a wear-resistant coating (Fig. 7). It is possible that considerable drop of cutting force mentioned in [32-34] is the result of, among other things, the above.

\section{Conclusions}

- Through the example of replaceable indexable milling inserts offered by Sandvik Coromant, which have (AlTi) $\mathrm{N}$ coating with a surface anti-adhesion layer, we studied a tool having efficient cutting properties. Formation of the buildup of a machined nickel alloy blank at the cutting edge of a cutting insert is minimal. Because of this specificity, the tool demonstrated an outstanding wear resistance, especially at run-in area, despite the lowest value of coating microhardness. In the course of wearing out of the anti-adhesion layer, cutting properties of the insert approach to the properties of a (TiAl)N-ML coated insert;

- application of DLC film expectedly did not affect on adhesion interaction of the machined material and the tool in the areas adjacent to cutting edges. However, owing to low friction factor of the film and the heatresistant alloy, we were able to affect the character of chip formation;

- abrasive wear resistance of a tool can be enhanced using electron-beam alloying of a hard-alloy tool surface with high-melting carbides. The near-surface layer consists of non-stoichiometric niobium, hafnium and tungsten carbides which allow reinforcing the cutting edge. The effect is most noticeable in intensive cutting modes when stresses occur in the area of the cutting edge with reach values that are close to the endurance strength of the hard alloy;

- the Certain contribution of adhesion and abrasion wear can be presumed to be roughly equal. By creating wearresistant coatings of the different application on the hard alloy surfaces and inside the wear-resistant coating, it becomes possible to effect pointedly on each of the wear process components. However, the insufficient resistance of the tool to one of the wear types may act as the limiting factor in the machining process.

Acknowledgments. The financial support provided by the Ministry of Education and Science of the Russian Federation, in the framework of the state task in the field of scientific activity of MSTU "STANKIN" (No 11.1817.2017/4.6).

The work is carried out on the equipment of the Center of collective use of MSTU "STANKIN".

\section{References}

[1] S.N. Grigoriev, Study of cutting properties and wear pattern of carbide tools with comprehensive chemical-thermal treatment and nano-structured/gradient wear-resistant coatings, Mechanics \& Industry 17 (2016) 702

[2] V.V. Kuzin, M.Yu. Fedorov, M.A. Volosova, Nitride ceramic surface layer stressed state transformation with a change in TiC-coating thickness. Stress - distributed force load version, Refract. Ind. Ceram. 57 (2017) 551-556

[3] P.H. Bottger, E. Lewin, J. Patscheider, V. Shklover, D.G. Cahill, R. Ghisleni, M. Sobiech, Thermal conductivity of hard oxynitride coatings, Thin Solid Films 549 (2013) 232-238

[4] J. Nohava, P. Dessarzin, P. Karvankova, M. Morstein, Characterization of tribological behavior and wear mechanisms of novel oxynitride PVD coatings designed for applications at high temperatures, Tribol. Int. 81 (2015) 231-239

[5] S.N. Grigoriev, S.V. Fedorov, Tool material surface alloying by wide-aperture low-energy high-current electron-beam treatment before wear-resistant coating, Mechanics \& Industry 16 (2015) 710

[6] S.N. Grigoriev, S.V. Fedorov, Tool surface microalloying by self-extending high-temperature synthesis, Mater. Sci. Forum 834 (2015) 21-28

[7] S.N. Grigoriev, S.V. Fedorov, M.D. Pavlov, A.A. Okunkova, Y.M. Soe, Complex surface modification of carbide tool by NbHfTi alloying followed by hardfacing (TiAl)N, J. Frict. Wear 34 (2013) 14-18

[8] Z.-L. Li, D. Ye, Z. Li-Min, Accurate cutting force prediction of helical milling operations considering the cutter runout effect, Int. J. Adv. Manuf. Technol. 92 (2017) 1-12

[9] A.B. Markov, E.V. Yakovlev, V.I. Petrov, formation of surface alloys with a low-energy high-current electron-beam 
for improving high-voltage hold-off of copper electrodes, IEEE Trans. Plasma Sci. 41 (2013) 2177-2182

[10] L. Meisner, A. Markov, V.P. Rotshtein, et al., Microstructural characterization of Ti-Ta-based surface alloy fabricated on TiNi SMA by additive pulsed electron-beam melting of film/substrate system, J. Alloys Compd. 730 (2018) 376-385

[11] S.V. Fedorov, G.V. Oganyan, Special features of electronbeam alloying of replaceable polyhedral hard-alloy plates under a complex surface treatment, Met. Sci. Heat Treat. 57 (2016) 620-624

[12] S.N. Grigoriev, A.S. Metel, S.V. Fedorov, Modification of the structure and properties of high-speed steel by combined vacuum-plasma treatment, Met. Sci. Heat Treat. 54 (2012) 8-12

[13] K. Lukaszkowicz, E. Jonda, J. Sondor, K. Balin, J. Kubacki, Characteristics of the AlTiCrN + DLC coating deposited with a cathodic arc and the PACVD process, Mater. Technol. 50 (2016) 175-181

[14] B. Karpuschewski, J. Kundrak, T. Emmer, D. Borysenko, A New Strategy in Face Milling - Inverse Cutting Technology, Solid State Phenom. 261 (2017) 331-338

[15] M. Rief, B. Karpuschewski, E. Kalhöfer, Evaluation and modeling of the energy demand during machining, CIRP J. Manuf. Sci. Technol. 19 (2017) 62-71

[16] A.A. Andreev, O.V. Sobol', I.V. Serdyuk, et al., Synthesis of refractory carbide and nitride phases at the surface electronbeam alloying of tool materials, J. Frict. Wear 35 (2014) 497-500

[17] S.V. Fedorov, A.A. Okunkova, N.Yu. Peretyagin, P.Yu. Peretyagin, Electroconductive graphene-hydroxyapatite PVD targets for magnetron sputtering, Izvestia vyshih uchebnyh zavedeniy. Fizika 59 (2016) 192-194

[18] M.M. Stebulyanin, A.A. Gurkina, A.A. Shein, N.Yu. Cherkasova, Measuring adhesive bond strength and microhardness of multilayer composite wear-resistant coating, Mechanics \& Industry 17 (2016) 712

[19] T. Mulyana, E. Abd Rahim, S.N. Md Yahaya, The influence of cryogenic supercritical carbon dioxide cooling on tool wear during machining high thermal conductivity steel, J. Cleaner Prod. 164 (2017) 950-962

[20] A. Czana, M. Sajgalika, J. Holubjaka, et al., Identification of Temperatures in Cutting Zone when Dry Machining of Nickel Alloy Inconel 718, Procedia Manuf. 14 (2017) 66-75

[21] P. Ruitao, T. Heng, T. Xinzi, Z. Zhuan, FEM-DEM coupling simulations of the tool wear characteristics in prestressed machining superalloy, MATEC Web of Conferences 80 (2016) 04001
[22] Z. Pan, Y. Feng, S.Y. Liang, Material microstructure affected machining: a review, Manufacturing Rev. 4 (2017) 5

[23] O.M. Oduola, O.O. Awopetu, C.A. Ikutegbe, K.J. Akinluwade, A.R. Adetunji, An Outlook on Tool Wear Mechanisms of Selected Cutting Tool Materials, Br. J. Appl. Sci. Technol. 14 (2016) 1-9

[24] X. Cui, B. Zhao, F. Jiao, P. Ming, Formation characteristics of the chip and damage equivalent stress of the cutting tool in high-speed intermittent cutting, Int. J. Adv. Manuf. Technol. 91 (2017) 2113-2123

[25] C. Dai, W. Ding, J. Xu, C. Ding, G. Huang, Investigation on size effect of grain wear behavior during grinding nickelbased superalloy Inconel 718, Int. J. Adv. Manuf. Technol. $91(2017) 1-11$

[26] B. Kursuncu, H. Caliskan, S.Y. Guven, P. Panjan, Wear Behavior of Multilayer Nanocomposite TiAlSiN/TiSiN/ TiAlN Coated Carbide Cutting Tool during Face Milling of Inconel 718 Superalloy, J. Nano Res. 47 (2017) 11-16

[27] N.H. Razak, M.M. Rahman, K. Kadirgama, Cutting force and chip formation in end milling operation when machining nickel-based superalloy, Hastelloy C-2000, J. Mech. Eng. Sci. 11 (2017) 2539-2551

[28] A. Suarez, et al., Effects of high-pressure cooling on the wear patterns on turning inserts used on alloy IN718, Mater. Manuf. Processes 32 (2017) 678-686

[29] I. Smurov, M. Doubenskaia, S. Grigoriev, A. Nazarov, Optical Monitoring in Laser Cladding of Ti6Al4V, J. Therm. Spray Technol. 21 (2012) 1357-1362

[30] S.N. Grigor'ev, S.V. Fedorov, M.D. Pavlov, et al., Complex surface modification of carbide tool by Nb plus Hf plus $\mathrm{Ti}$ alloying followed by hardfacing (Ti plus Al)N, J. Frict. Wear 34 (2013) 14-18

[31] V.I. Medvedev, et al., Mathematical model and algorithm for contact stress analysis of gears with multi-pair contact, Mech. Mach. Theory 86 (2015) 156-171

[32] S.V. Fedorov, M.D. Pavlov, A.A. Okunkova, Effect of structural and phase transformations in alloyed subsurface layer of hard-alloy tools on their wear resistance during cutting of high-temperature alloys, J. Frict. Wear 34 (2013) 190-198

[33] A.A. Andreev, et al., Tribological characteristics of nanocomposite vacuum-plasma Ti-Hf, Ti-Hf-N, and Ti-Hf-Si-N coatings, J. Frict. Wear 34 (2013) 175-182

[34] V.V. Kuzin, S.N. Grigor'ev, M.A. Volosova, Thermal and Deformation Processes Occurring Within a Component Surface Layer Made from Oxide-Carbide Ceramic in Contact with a Nickel Alloy Component During Heating, Refract. Ind. Ceram 55 (2014) 157-163 